\title{
The Great Chukchansi Yokuts Iambic Conspiracy*
}

\author{
Peter Ara Guekguezian \\ University of Southern California
}

\section{Introduction}

In this paper, I argue that Chukchansi Yokuts is an iambic language, i.e., it parses words into iambic Feet. This argument rests partly on novel stress data from Chukchansi that display quantity-sensitivity, contra the penultimate stress assumed for Yokuts based on Newman (1944). These data, collected by the researcher, show that non-final heavy syllables (CV: and CVC) always receive stress (1-2). Penultimate light syllables also receive stress, due to constraints preventing final stress and sequences of unstressed syllables (2-3).

Stress on Non-Final Heavy Syllables:

a. ['p'a:.ya] 'child-ACC'

b. ['bok'.to?] 'had found'

c. [he. 'ye:.ma] 'long ago'

d. [tyi.' Ja:.lat] 'just made cut'

e. ['k'et.la. 'han.ta?] 'had made be shaved'

f. [Pa.' le:.dza.' law. Jit] 'just made oneself crazy'

Stress on Heavy Non-Final and Light Penultimate Syllables:

a. ['tee:. 'xa.Pan] 'dog-ACC'

b. ['le:.' le?.'hi.yaw] 'at school'

c. ['yun.' Ju.nut] 'just shook'

d. [li. 'him. 'wi.fe?] 'will run with each other'

e. ['be:.' win.ha.' na.Pan] 'sewn thing-ACC'

Stress on Light Penultimate Syllables:

a. [' 'a.lit]'long ago' (synonymous with [he. 'ye:.ma])

b. ['p'i.je?] 'will light'

These findings mostly agree with Collord's (1968) and Mello's (2012) generalizations about Chukchansi stress, though they differ from Newman's (1944) description of penultimate stress in Yokuts. The stress system outlined above can be captured equally well with moraic trochees or with iambs. However, three other phonological facts show convincingly that an iambic analysis is more explanatory than a trochaic one. First, when epenthesis occurs to repair unsyllabifiable triconsonantal clusters, the position of the epenthetic vowel always results in a light-heavy (LH), not a heavy-light (HL), syllable sequence. While both sequences are phonotactically well-formed, the preference for LH over HL suggests that the former sequence is more harmonic than the latter in Chukchansi. An LH sequence is more harmonically parsed than an HL sequence in an iambic system, while both are equally well-formed in a trochaic system. Secondly, the inventory of verb roots is skewed toward shapes that are parsed faithfully into $\mathrm{H}$ or LH sequences. Roots that could be parsed into LL sequences are relatively rare; since LL sequences tend to be disharmonic in iambic but not in trochaic systems, their paucity in Chukchansi suggests that it is iambic. Finally, the fact that suffix-based root shape change almost always results in an LH sequence also suggests that LH is a privileged structure in Chukchansi, which again makes perfect sense in an iambic system, but is unexplained in a trochaic system. I thus propose that iambs are the fundamental building blocks of prosodic structure in Chukchansi Yokuts.

\footnotetext{
* I thank my Chukchansi Yokuts consultant, Holly Wyatt, for her patience, intelligence, and willingness to share her linguistic heritage. I also that the linguistics faculty at California State University, Fresno, for their help both with gathering the data and thinking about how to analyze them. My adviser, Karen Jesney, provided great input for this analysis, as did the audiences at PhonLunch at the University of Southern California. This research is supported by a Research Enhancement Fellowship from the University of Southern California.
}

(C) 2015 Peter Ara Guekguezian

Proceedings of AMP 2014

Completed March 8, 2015 


\section{Theoretical Background: Iambic Well-Formedness}

I make some theoretical assumptions about iambic stress systems. Iambic stress is right-headed, and according to the Iambic-Trochaic Law (e.g., Hayes 1995), grounded in perception, prefers to be uneven, with the stressed syllable longer in duration than the unstressed. This gives the light-heavy (L'H) Foot as optimal in the above point of view; the stressed 'H syllable is longer than the unstressed L syllable (Hayes 1995). Kager $(1993,1995)$ also has (L'H) being the optimal iamb, though his reasoning is different. The (L'H) Foot in Kager's view is an optimal iambic configuration, in that its stressed mora is in the middle of the Foot $\left[\mu^{\prime} \mu \mu\right]$, avoiding mora lapse $\left({ }^{*}\left[{ }^{\prime} \mu \mu \mu\right]\right.$ or $\left.*\left[\mu \mu^{\prime} \mu\right]\right)$ and a final stressed element $\left({ }^{*}\left[\mu^{\prime} \mu\right]\right)$ (which are both marked cross-linguistically), as well an initial stressed element $\left({ }^{*}\left[{ }^{\prime} \mu \mu\right]\right.$, which is not as clearly iambic). Prince (1990) also agrees with Kager and Hayes that ( $\left.\mathrm{L}^{\prime} \mathrm{H}\right)$ is the optimal Foot in an iambic system, according to principles of Grouping Harmony and preference for stressed elements to branch; ('H) and (L'L) are less well-formed iambs. The three possible iambic Feet have the following metrical structure (Figure 1): ${ }^{1}$

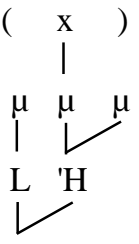

Foot (L'H)

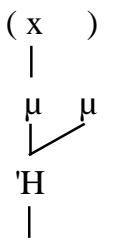

Foot ('H)

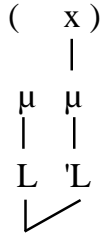

Foot (L'L)

There is debate over the relative well-formedness of ('H) and (L'L) Feet in iambic systems. For Prince (1990) and Hayes (1995) both ('H) and (L'L) Feet depart equally from the optimal (L'H), since both Feet are even. For Kager $(1993,1995)$, on the other hand, the ('H) Foot is more well-formed than the (L'L) Foot, as the (L'L) Foot has final prominence, which is cross-linguistically ill-formed at all levels: Word (e.g., Prince and Smolensky 1993/2004), Foot, and Syllable (Kager 1995, Hyde 2007). The Chukchansi Yokuts data support Kager's $(1993,1995)$ tripartite hierarchy of iambic well-formedness: (L'H), the optimal Foot, is the target of root shape change and vowel epenthesis, while both $(\mathrm{L} ' \mathrm{H})$ and $(' \mathrm{H})$ Feet, but not $(\mathrm{L} / \mathrm{L})$, are good stress Feet. Moreover, the inventory of root shapes overwhelmingly favors roots that are easily parsed into ('H) or (L'H) Feet (i.e., without violating Faithfulness) to roots that would be parsed into (L'L) Feet. These data favor an iambic system in which ( $\left.\mathrm{L}^{\prime} \mathrm{H}\right)$ is the most well-formed foot and (L'L) the least, with ('H) in-between (4).

$$
\text { Iambic Well-formedness Scale: }\left(\mathrm{L}^{\prime} \mathrm{H}\right) \prec\left(\text { 'H) } \prec\left(\mathrm{L}^{\prime} \mathrm{L}\right)\right.
$$

Table 1. Chukchansi Iambic Well-Formedness Scale (Kager 1993, 1995; cf. Prince 1990, Hayes 1995)

\begin{tabular}{|c||c||c|}
\hline L'H (most well-formed $=$ optimal) & 'H & L'L (least well-formed) \\
\hline \hline $\begin{array}{c}\text { Root Shape Change } \\
\text { Epenthesis }\end{array}$ & *DISHARMONIC \\
\hline \multicolumn{2}{c|}{$\begin{array}{c}\text { Stress Feet } \\
\text { Lexical Root Shape }\end{array}$} & *DISHARMONIC \\
\hline \hline
\end{tabular}

While I do not suggest that Prince (1990) and Hayes (1995) are wrong in the relatively equal well-formed of ( $\mathrm{L} ' \mathrm{~L})$ and ('H) Feet cross-linguistically, I do claim the evidence shows that ('H) Feet are more harmonic than (L'L) Feet in Chukchansi. This is due to the above dispreference for final prominence in prosodic units, e.g., the constraints Non-Finality(Ft) or Non-Finality( $\sigma)$ (Hyde 2007; see also Kager 1995). ${ }^{2}$ I use the constraint NON-FinALITY(Ft) to penalize ( $\mathrm{L}$ 'L) Feet, in which the stressed mora is Foot-final.

$$
\text { NON-FINALITY(Ft): Assign a violation mark for a stress occurring over the final mora of a Foot. }
$$

\footnotetext{
${ }^{1}$ I do not include degenerate ('L) Feet, which violate high-ranked FoOTBINARITY (McCarthy and Prince 1986, 1993; Kager 1993; Hayes 1995). ('L) Feet do not appear in most (quantity-sensitive) languages, including Chukchansi.

2 (L'L) Feet are also penalized by a general dispreference for stressed light syllables, e.g., the constraint Stress-to-Weight Principle (SWP; Prince 1990, Crosswhite 1998).
} 


\section{Stress}

This section presents new stress data on Chukchansi Yokuts. The generalizations found are similar to those in previous studies of Chukchansi stress, Collord (1968) and Mello (2012), apart from inconsistencies about primary versus secondary stress. These three studies all dispute Newman's (1944) account of (almost) exclusively penultimate stress in Yokuts. I capture Chukchansi stress primarily with ('H) and (L'H) iambs, while a dispreference for (L'L) iambs and final consonant extrametricality can result in a final ('LL) trochee.

3.1 Generalizations I begin by presenting data from a new study of Chukchansi Yokuts stress conducted on two separate occasions. While there are a few inconsistencies in the data, most of the words show the patterns in (6-9). Apparent departures from these patterns always involve words where multiple stresses would be expected, but one of the stresses was not transcribed; stress was never transcribed on syllables that these patterns predict to be unstressed. Disyllabic words are always stressed on the penultimate syllable (6).

$$
\text { Disyllables—Penultimate Stress: ['p'a:.ya] ['bok'.to?] ['?a.lit] ['p'i.fe?] }
$$

Trisyllabic words have stress on the penultimate syllable (7-8); a heavy initial syllable is also stressed (8).

$$
\begin{array}{lll}
\text { Trisyllables_Penultimate Stress: } & \text { [he. 'ye:.ma] } & \text { [tfi.' Ja:.lat] } \\
\text { Trisyllables_-Initial and Penultimate Stress: ['tfe:.' 'xa.Pan] } & \text { ['yun.' Ju.nut] }
\end{array}
$$

Longer words show the same patterns as in (7-8): the penultimate syllable is stressed, as are all heavy syllables before the penult (9).

$$
\begin{aligned}
& \text { Polysyllables —Penultimate and Pre-penultimate Heavy Stress: ['k'et.la.' han.ta?] } \\
& \text { ['le:.'le?.'hi.yaw] [li.'him.'wi.Je?] [?a.'le..duga.'law.Jit] ['be:.'win.ha.'na.Pan] }
\end{aligned}
$$

No consistent distinction between primary and secondary stresses was found: often, the penultimate syllable seemed to have primary stress, but sometimes a pre-penultimate syllable did. I set degrees of stress aside, as these are not crucial for the analysis below, though a consistent generalization should be found in the future.

Based on these data, the correct generalizations of Chukchansi stress are as follows (10-13):

(10) Penultimate syllables are always stressed, whether CV (a), CVC (b), or CV: (c)
a. [' $\underline{\text { a }} \cdot$.lit $]$
['p'i.je?]
[li.'him.'wi.je?] ['le:.'le?.'hi.yaw]
['ye:.'xa.Pan]
['yun. '[u.nut]
b. ['bok'.to?] ['k'et.la.' han.ta?]
c. ['pa:.ya]
[he.' ye:.ma]
['be:.'win.ha.'na.Pan]
[Pa.' le:.dza.' 'law. .jit]
[ti.' [a:.lat]

(11) Final syllables are never stressed, neither CV (a) not CVC (b) (no final CV: syllables exist)
a. *[he.ye:.' $\underline{\text { ma }]}$
b. *[?a.' lit]
*['bok'.'to?]
*['te:.xa.' ?an]
*[?a.' le:.dza.' law.' [it]
All heavy pre-penultimate syllables are stressed, both CVC (a) and CV: (b)
a. ['yun.' Ju.nut] [li.' 'him.'wi.je?] ['k'et.la.'han.ta?] ['le:.' le?.'hi.yaw] ['be:.'win.ha.'na.Pan]
b. ['tee:.'xa.Pan] ['le:.' 'le?.'hi.yaw] [Pa.'le:.dza.' 'law.fit] ['be:.'win.ha.'na.Pan]
No pre-penultimate CV syllables are ever stressed

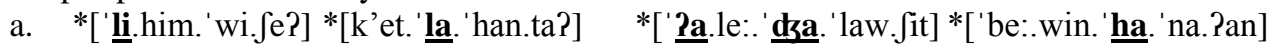

This system is quantity-sensitive: all heavy syllables receive stress, with non-finality forcing stress on light penultimate syllables to avoid a two-syllable lapse. I now show that Chukchansi stress is amenable to analysis with iambic Feet. Chukchansi Feet are preferably ('H) or (L'H), and these are constructed left-toright (as in the vast majority of iambic systems; see, e.g., Hayes 1995), so that the first Foot is always word-initial (14).

$$
\begin{aligned}
& \text { Left-to-Right Iambs: [('p'a:).ya] } \\
& \text { [(tgi.'Ja:).lat] [('k'et).(la.'han).ta?] [(Pa.'le:).(dza.'law).jit] } \\
& \text { [(he.'ye:).ma] }
\end{aligned}
$$


However, a strict observance of non-finality (i.e., no stress on a final syllable) causes placement of a final ('LL) trochee if the penult is light, in order to avoid these last two syllables being unstressed (assuming that the final consonant is extrametrical, as ('LH) Feet are likely impossible in any language) (15).

$$
\text { ('LL) Trochee: [('Pa.li)t] [('p'i.fe)?] }
$$

Many words with three or more syllables begin in ('H) or (L'H) iambs and end in a final ('LL) trochee (16).

$$
\begin{aligned}
& \text { Left-to-Right Iambs + Final ('LL) Trochee: [('te:).('xa.Pa)n] [('le:).('le?).('hi.ya)w] } \\
& \text { [('yun).('fu.nu)t] [(li.'him).('wi.fe)?] [('be:).('win).ha.('na.Pa)n] }
\end{aligned}
$$

3.2 Comparison with Previous Accounts The above generalizations seem to be at odds with Newman's (1944) description of Yokuts stress as almost exclusively penultimate ${ }^{3}$ On the other hand, these generalizations agree almost entirely with Collord's (1968) description of Chukchansi stress. However, Collord (1968) distinguishes primary from secondary stress:

"Primary stress ... is on the penultimate syllable ... a secondary stress is found on the closed [i.e., heavy] syllables (non-penult) ... non-penultimate open [i.e., light] syllables are weakly stressed."

(Collord 1968:14)

Disregarding the distinction between primary and secondary stress, Collord's findings agree with the generalizations above (10-13), except that he finds a secondary stress on final heavy syllables. He notes, however, that both final heavy and final light syllables have the same low pitch, while pre-penultimate heavy syllables have medium or high pitch. I take this to indicate that final heavy syllables are actually unstressed, which is supported by the extreme rarity of final long vowels in Chukchansi, unexpected if final vowels can be stressed. Lack of final stress also prevents describing CVCVC words as *['L'H], which would be extremely odd given what is known about stress systems (17).

Improbable ['L'H] Words: ?['?a.' lit], ?['p'i.' 'e?]

Mello (2012) finds that stress is generally penultimate, but shifts to an antepenult with a long vowel (CV:), and is thus quantity-sensitive. ${ }^{4}$ While his generalizations give the same stress patterns as the new study does for most words (18), they drop one of the stresses in some trisyllabic words (19).

$$
\begin{aligned}
& \text { Data Identical to Mello (2012): ['pa:.ya] ['bok'.to?] ['Pa.lit] ['p'i.fe?] } \\
& \text { [he.'ye:.ma] [tfi.'Ja:.lat] } \\
& \text { Data Different from Mello (2012): } \\
& \text { a. ?['te:.xa.Pan] (Mello) instead of ['fe:.'xa.Pan] (here) } \\
& \text { b. ?[yun.'.Ju.nut] (Mello) instead of [' yun.'.Ju.nut] (here) }
\end{aligned}
$$

Mello's study has methodological issues (e.g., usage of non-Chukchansi phonemes in nonce words, focus on disyllabic and trisyllabic words), and makes several untenable conclusions, such as that codas are never moraic, and that long vowels cannot occur before the antepenult. Nevertheless, Mello's findings fall in line with Collord's and the new study's, if his generalization is instead about primary stress: while penults in general have primary stress, a preceding long vowel can attract primary stress away. This follows from long vowel rimes (V:) being inherently more prominent that short vowel + coda rimes (VC), as shown by, e.g., Zoll (1996) and Gordon (2004, 2006), and O'Connor (2011). The penult still has a secondary stress, as do closed (CVC) pre-penultimate syllables; likely Mello did not observe these, perhaps since stresses in consecutive syllables are difficult to pick up (as I can attest in the new study). A close study of Mello's pitch tracks and intensity data suggests that these secondary stresses are real. The difference between Collord's and Mello's generalizations may thus be a difference in position of primary stress between the speakers they

\footnotetext{
${ }^{3}$ Newman (1944:28) does note that certain suffixes (which he terms "auxiliaries") are outside of the stress domain, and that "a few three-syllable noun having a strong [i.e., long] vowel in the first syllable ... are stressed on the antepenult", e.g., Wikchamni ['ne:.pa.yi] "wife's brothers."

${ }^{4}$ Mello's (2012) study consulted the same Chukchansi speaker as the new study.
} 
consulted; the footing will be the same for both speakers. Setting aside degrees of stress, the generalizations from the new study in $\$ 3.1$ do not conflict with Collord's or Mello's findings. I therefore assume the Footing in forms (14)-(16) above, remaining agnostic about which stresses are primary and which secondary.

3.3 Account This section shows that Chukchansi stress is amenable to an analysis with iambic parsing. Iambic parsing requires ranking IAMB and PARSE- $\sigma$ over TROCHEE (e.g., Prince and Smolensky 1993/2004, McCarthy and Prince 1993).

(20) IAMB: assign a violation mark to any Foot with the rightmost syllable unstressed. (*'LL, *'HL)

(21) PARSE- $\sigma$ : assign a violation mark to any syllable not dominated by a Foot.

(22) TROCHEE: assign a violation mark to any Foot with the leftmost syllable unstressed. ( ${ }^{2} \mathrm{~L}$ 'L, $\left.{ }^{*} \mathrm{~L} ' \mathrm{H}\right)$

According to (20), (L'L), ('H), and (L'H) are all possible iambs (they do not violate IAMB). The ranking of IAMB and PARSE- $\sigma$ over TROCHEE correctly foots all data with a heavy penult ((23), repeated from (14)):

$$
\begin{aligned}
& \text { Heavy Penults: [('pa:).ya] } \\
& \text { [('bok').to?] } \\
& \text { [(he.'ye:).ma] } \\
& \text { [(tgi.' fa:).lat] } \\
& \text { [('k'et).(la.'han).ta?] } \\
& \text { [('Pa.' le:).(dza.' law).jit] }
\end{aligned}
$$

\begin{tabular}{|c|c|c|c|}
\hline /Rale:dza-la-wf-it/ & IAMB & PARSE- $\sigma$ & TROCHEE \\
\hline$\varpi$ [(Pa.'le:).(dza.' law).Jit] & & * & ** \\
\hline [?a.('le:).dza.('law).fit] & & $* * * \mathrm{~W}$ & $\mathrm{~L}$ \\
\hline [Pa.('le:.dza).('law).fit] & $* \mathrm{~W}$ & $* * \mathrm{~W}$ & $\mathrm{~L}$ \\
\hline
\end{tabular}

Table 2. IAMB, PARSE- $\sigma>>$ TROCHEE: (L'H)X

\begin{tabular}{|l|c|c|c|}
\hline /heye:ma/ & IAMB & PARSE- $\sigma$ & TROCHEE \\
\hline [(he.'ye:).ma] & & $*$ & $*$ \\
\hline [he.('ye:).ma] & & $* * \mathrm{~W}$ & $\mathrm{~L}$ \\
\hline [he.('ye:.ma)] & $* \mathrm{~W}$ & $*$ & $\mathrm{~L}$ \\
\hline
\end{tabular}

Table 3. IAMB, PARSE- $\sigma$ > TROCHEE: (L'H)(L'H)X

In order to place a final ('LL) trochee on a word with a light penult ((24), repeated from (15-16)), IAMB must be dominated by other constraints.

$$
\begin{aligned}
& \text { Light Penults: [('Pa.li)t] [('p'i.fe)?] [('tfe:).('xa.Pa)n] [('le:).('le?).('hi.ya)w] } \\
& \text { [('yun).('Ju.nu)t] [(li.'him).('wi.fe)?] [('be:).('win).ha.('na.Pa)n] }
\end{aligned}
$$

For example, the input/?alit/ could hypothetically receive any of the following iambic parsings below, instead of its actual trochaic parsing [(' 'a.li)t] (25):

$$
\text { Hypothetical Iambic Parsings: *[(Pa.' lit)] *[(?a.' li:)t] *[(?a.' li)t] }
$$

Each of these iambic output candidates must be eliminated by a constraint that both dominates IAMB and is not violated by the winning candidate [(' Pa.li)t]. [(?a.' lit)] has an $\left(\mathrm{L}^{\prime} \mathrm{H}\right)$ Foot whose stressed syllable is made heavy by a coda, which violates ${ }^{*} \mathrm{C}_{\mu}$ (Morén 1999). [(Pa.li)t] satisfies ${ }^{*} \mathrm{C}_{\mu}$ by leaving the final consonant unparsed and thus not moraic; this violates PARSE-SEG(FIN) (Elfner to appear).

${ }^{*} \mathrm{C}_{\mu}$ : assign a violation mark to a consonant dominated by a mora.

$$
\text { PARSE-SEG(FIN): assign a violation mark to a PWd-final segment not dominated by a syllable. }
$$

${ }^{*} \mathrm{C}_{\mu}$, which only [(Pa.' lit)] violates, dominates both PARSE-SEG(FIN) and IAMB, which only [(' 'a.li)t] violates.

Table 4. $* \mathrm{C}_{\mu} \gg$ > PARSE-SEG(FIN), IAMB: ('LL)

\begin{tabular}{|l|c|c|c|}
\hline$/$ Ralit/ & $* \mathrm{C}_{\mu}$ & PARSE-SEG(FIN $)$ & IAMB \\
\hline$[($ ' 'a.li)t $]$ & & $*$ & $*$ \\
\hline$\left[\left(\right.\right.$ Pa.'lit $\left.\left.\mu_{\mu}\right)\right]$ & $* \mathrm{~W}$ & $\mathrm{~L}$ & $\mathrm{~L}$ \\
\hline
\end{tabular}


The (L'H) Foot of [(Pa.' li:)t] is formed by lengthening the final vowel. This violates DEP- $\mu$, which penalizes epenthesis of a mora (Keer 1999, Morén 1999, McCarthy 2000). ${ }^{5}$

(28) DEP- $\mu$ : assign a violation mark to a mora in the output without an input correspondent

DEP- $\mu$, which penalizes [(Pa.'li:)t], dominates IAMB.

Table 5. DEP- $\mu$ > IAMB: ('LL)

\begin{tabular}{|l|c|c|}
\hline$/$ Palit/ & DEP- $\mu$ & IAMB \\
\hline$[($ ' Pa.li)t $]$ & & $*$ \\
\hline$[($ Pa.'li: $) \mathrm{t}]$ & $* \mathrm{~W}$ & $\mathrm{~L}$ \\
\hline
\end{tabular}

Lastly, [(Pa.'li)t] obeys IAMB with an (L'L) Foot, which violates NON-FINALITY(Ft), as shown in §2; thus, NON-FINALITY(Ft) dominates IAMB as well.

Table 6. NON-FINALITY(Ft) >> IAMB: ('LL)

\begin{tabular}{|l|c|c|}
\hline$/$ Ralit/ & NON-FINALITY(Ft) & IAMB \\
\hline$[($ ' 'a.li)t $]$ & & $*$ \\
\hline$[($ ?a.'li)t $]$ & $* \mathrm{~W}$ & $\mathrm{~L}$ \\
\hline
\end{tabular}

A longer input with a potentially light penult, such as / $\mathrm{fe}: \mathrm{xa}-\mathrm{Pan} /$, could avoid a final ('LL) trochee by leaving the last two syllables unparsed *[('fe:).xa.Pan]. Since PARSE- $\sigma$ is dominated by IAMB, the constraint *LAPSE (e.g., Selkirk 1984, Kager 1993) is needed to penalize this candidate and favor [('fe:).('xa.Pa)n].

*LAPSE: assign a violation mark to any sequence of two unstressed syllables.

Table 7. *LAPSE > IAMB: ('H)('LL)

\begin{tabular}{|c|c|c|}
\hline /tge:xa-Pan/ & *LAPSE & IAMB \\
\hline [('te:).('xa.Pa)n] & & $*$ \\
\hline [('te:).xa.?an] & $* \mathrm{~W}$ & $\mathrm{~L}$ \\
\hline
\end{tabular}

Because IAMB outranks PARSE- $\sigma$ and TROCHEE, non-final Feet are always iambic, either ('H) or (L'H). A hypothetical input that would faithfully map to an LL sequence before the penult is needed to determine the relative ranking of DEP- $\mu$, NON-FINALITY(Ft), and *LAPSE. Such a form has not been elicited, and would be vanishingly rare due to the lexical skew away from roots that map to LL sequences, (see §5).

The careful reader will have noted that the stress data above also admit of an analysis with moraic trochees. Moraic trochees would place stress on all heavy syllables ('H), as well as on the penult in a final LL sequence ('LL). Words with only ('H) or ('LL) Feet (e.g., [(' 'a.li)t], [('te:).('xa.Pa)n]) would be footed identically to the iambic analysis, while words with ( $\mathrm{L}$ 'H) Feet would be replace these with ('H) Feet (30).

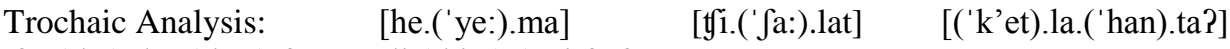

$$
\begin{aligned}
& \text { [?a.('le:).dza.('law).jit] [li.('him).('wi.Je)?] }
\end{aligned}
$$

Evidence for Chukchansi Yokuts being iambic and not trochaic comes from other parts of the phonology, including epenthesis, the lexical root inventory, and root shape change.

\footnotetext{
${ }^{5}$ A thorough account of suffix-based root shape change (see §6) prevents DEP- $\mu$ from being the actual constraint used here. Rather, a constraint is needed to penalize vowel lengthening specifically, i.e., it only penalizing epenthetic morae attached to vowels with an input correspondent, not those attached to epenthetic vowels. This additional constraint is crucial, due to the lower ranking of DEP- $\mu$ in a full analysis of root shape change, in which epenthetic long vowels may appear (see $§ 6$, as well as Guekguezian (to appear)). This constraint is essentially the conjunction of IDENT-V(LONG) and DEP- $\mu$ in the domain of a segment: an epenthetic mora is penalized if it lengthens an input short vowel.
}

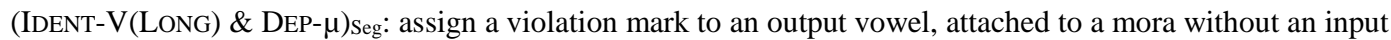
correspondent, that differs in length from its corresponding input vowel 


\section{Epenthesis}

Patterns of vowel epenthesis suggest that Chukchansi is iambic, not trochaic. A shown for Yowlumne Yokuts in, e.g., Kisseberth (1970), Kenstowicz and Kisseberth (1979), clusters of three consonants do not exist on the surface in Chukchansi, since three consonants cannot fit in the margins of two consecutive syllables without forming an illegal tautosyllabic cluster. In a string of three input consonants, a high vowel is epenthesized between the first and second consonant: /CCC/ -> [CiCC]. Zoll (1993) proposes two alignment constraints, ALIGN-R(Morph, $\sigma$ ) and ALIGN-R(Template, $\sigma$ ), that correctly predict the position of the epenthetic vowel. However, these constraints miss a bigger generalization: the position of the epenthetic vowel creates optimal Chukchansi prosodic structure, an initial (L'H) iamb. For example, when the root /lihm/ 'run' attaches to the suffix /-ta?/ 'REM.PAST', the result is [(li.'him).ta?], with an initial (L'H) Foot, not *[('lih).('mi.ta)?], with an ('H) Foot followed by an ('LL) trochee (32). The general pattern is shown in (31).

$$
\begin{aligned}
& \text { *CCC Epenthesis: /lihm-ta?/ } \rightarrow[(\text { li.'him).ta?] } \prec *[(' l i h) .(' m i . t a) \text { ? }] \\
& \text { *CCC Epenthesis: /CVCCCV.../ } \rightarrow[(C V . ' C i C) . C V . . .], *[(' C V C) .(C i . C V . . .]
\end{aligned}
$$

Three consonant clusters mainly occur when one-vowel roots with three consonants attach to consonantinitial suffixes (31). The main question this poses is why the epenthetic vowel occurs between the first and second consonants rather than the second and third, i.e., why /lihm+ta?/ surfaces as [li.him.ta?], not *[lih.mi.ta?]. Both output candidates have exactly one violation of faithfulness (DEP-V), and are equally harmonic phonotactically. Under an iambic analysis, the reason is immediately clear: [(li.'him).ta?] is parsed into an optimal iamb (L'H), but [('lih).('mi.ta)?] contains a trochee ('LL). Ranking IAMB over both TROCHEE and PARSE- $\sigma$ chooses [(li.'him).ta?] over [('lih).('mi.ta)?].

Table 8. IAMB >> TROCHEE, PARSE- $\sigma$ : Initial (L'H)

\begin{tabular}{|l||c|c|c|}
\hline$/$ lihm+ta?/ & IAMB & TROCHEE & PARSE- $\sigma$ \\
\hline \hline$[($ li.'him).ta?] & & $*$ & $*$ \\
\hline [('lih).('mi.ta)?] & $* \mathrm{~W}$ & $\mathrm{~L}$ & $\mathrm{~L}$ \\
\hline
\end{tabular}

The same ranking accounts for epenthesis that repairs others three consonant clusters, as in (33).

*CCC Epenthesis: /Rale:dza-la-wf-ta?/ 'crazy'-CAUS-RFLX-RM.PT $\rightarrow$ [(Pa.' le:).dza.(la. 'wif).ta?] $\prec *[($ Pa.'le:).dza.('law).(' Ji.ta)?] 'had made oneself crazy'

Table 9. IAMB >> TROCHEE, PARSE- $\sigma$ : Initial (L'H)

\begin{tabular}{|l||c|c|c|}
\hline /Rale:dza-la-wf-ta?/ & IAMB & TROCHEE & PARSE- $\sigma$ \\
\hline \hline [('a.' le:).dza.(la.' 'wif).ta?] & & $* *$ & $* *$ \\
\hline [('Pa.' le:).dza.('law).('Ji.ta)?] & $* \mathrm{~W}$ & $* \mathrm{~L}$ & $* \mathrm{~L}$ \\
\hline
\end{tabular}

While an iambic analysis of Chukchansi simply captures the position of epenthesis in the above situations, a trochaic analysis of Chukchansi stress cannot easily do so. Trochaic stress does not favor [li.('him).ta?] over *[('lih).('mi.ta)?] (or the *ClasH-avoiding parses *[('lih).mi.ta?] or *[lih.('mi.ta)?]), as both candidates contain well-formed bimoraic trochees. Picking the former candidate would require another, likely ad-hoc, constraint, such as the alignment constraints used in Zoll (1993). Under the iambic analysis, the selection of [(li.'him).ta?] (and the other cluster-repairing outputs shown above) is a TETU effect: when the grammar can freely choose between an iambic or a trochaic (i.e., poorly iambic) structure, it chooses the iambic one. The complete ranking of constraints so far is shown in the Hasse diagram below (Figure 2):

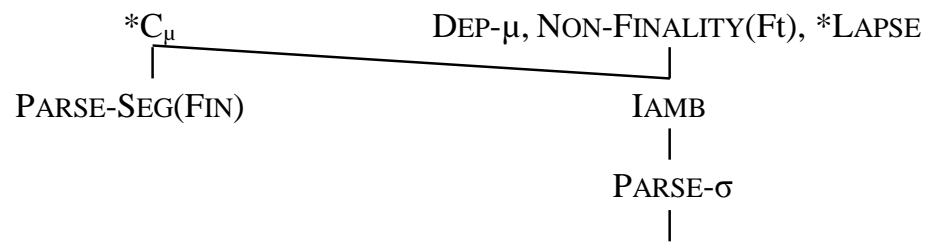

Figure 2. Stress + Epenthesis Constraint Ranking TROCHEE 


\section{Lexical Root Inventory}

More evidence that Chukchansi Yokuts is iambic comes from the inventory of verb root shapes in the lexicon. This section gives evidence suggesting that verb root shapes that are not easily parsed into good iambs are highly underrepresented in the lexicon. This relative lack of poorly iambic forms in the lexicon may be the result of active iambic parsing in the grammar, which seeps into the lexicon through optimization of input forms. Such an "iambic bias" is completely unexpected if Chukchansi is a trochaic language.

Setting the foundation for this argument requires establishing what makes a root a "good iamb." A wellestablished line of thought in phonological literature posits that input have no prosodic structure (i.e., no syllables or Feet). Because of the relatively simple and strict phonotactics of Chukchansi (syllables are either $\mathrm{CV}$ or CVX), and the absence of prefixes, the prosodic structure of the output of an input root is relatively stable across forms. The prosodic structure of output root forms depends on whether the first segment of the suffix directly attached is a consonant or a vowel. For example, when a $/ \mathrm{CVC} /$ root attaches to a /-V.../ suffix, the output form starts with a light (L) syllable [CV.C-V...] (34), while when it attaches to a /-C.../ suffixes, the output starts with a heavy (H) syllable [CVC.-C...] (35).

$$
\begin{aligned}
& \text { CVC Root with ('LL) Trochee: /p'if-e?/ 'light'-NPST } \rightarrow \text { [('p'i.je)?] } \\
& \text { CVC Root with ('H) Iamb: /p'if-ta?/ 'light'-RM.PT } \rightarrow \text { [('p'ii }) \text { ta?] }
\end{aligned}
$$

Some root types are always parsed into an initial ('H) or $(\mathrm{L} ' \mathrm{H})$ iamb, while others are not, due to an initial LL sequence. The difference between root types is essentially the difference between the initial (two) vowels. A root whose first vowel is long parses into an initial ('H) Foot no matter what material follows; even if a coda consonant shortens the long vowel in the output, that syllable is still heavy. If the first vowel is short, then the second vowel determines the root type: if it is long, the initial sequence is always $\mathrm{LH}$, resulting in an (L'H) Foot, while if it is short, the initial sequence is LL, unless a consonant cluster follows to create a second closed (heavy) syllable. An LL sequence would require either a poor iambic (L'L) Foot, an ('LL) trochee not motivated by non-finality, or unparsed syllables; none of these solutions are well-formed in Chukchansi. If there is no second root vowel, the initial sequence varies; usually it is $\mathrm{H}$ or LH (parsing into good iambic Feet), but in the case of a /CVC/ root attached to a V-initial suffix, the choice between an LL or LH sequence (i.e., between a good or bad iamb) depends on what further suffix material follows. VC sequences that always are mapped onto a closed (and thus, heavy) syllable due to a following root CV sequence, pattern with underlying long vowels (V:). Below is a table of the four possible root types (H, LH, LL, and L).

Table 12. Root Type Structure

\begin{tabular}{|l||l||l|}
\hline First Vowel? & Second Vowel? & Root Type \\
\hline \hline Long (or always Closed) & Does not Matter & H \\
\hline \multirow{3}{*}{ Short } & Long (or always Closed) & LH \\
\cline { 2 - 3 } & Short & LL \\
\cline { 2 - 3 } & None & L \\
\hline
\end{tabular}

According to the account of surface stress given in $\S 3, \mathrm{LH}$ and $\mathrm{H}$ roots are always parsed with a good initial iamb, ('H) or (L'H). L roots usually end up with a good iamb, but occasionally get parsed without one, while LL roots are sometimes parsed with, but often without, a good iamb. This suggests the following possible scale of relative root type well-formedness in Chukchansi (36).

$$
\text { Possible Root Well-formedness Scale: } \mathrm{H}, \mathrm{LH} \prec \mathrm{L} \prec \mathrm{LL}
$$

If this scale is correct, LL roots might be expected to be less common than the other root types in the Chukchansi lexicon. L roots might also be expected to be less common than $\mathrm{H}$ or LH roots, though more common than LL roots. By labeling and counting verb roots in the Chukchansi dictionary (Adisasmito et al. in progress), I have gained a preliminary perspective on whether this scale is correct. This involved eliminating repeated entries, derived entries (analyzable as a root plus suffix(es)), and loanwords from Spanish or English. This also required correcting several verb roots that have been mislabeled in the dictionary, as shown either by other forms in the Chukchansi corpus or direct elicitation. Table (13) below shows the revised count of Chukchansi verb root types. 
Table 13. Verb Roots by Type and Number of Consonants

\begin{tabular}{|l|l||l|}
\hline Number of Consonants & Root Type & Number of Roots \\
\hline \hline 1 & H & 2 \\
\hline \hline \multirow{5}{*}{2} & L & 82 \\
\cline { 2 - 3 } & H & 52 \\
\cline { 2 - 3 } & LL & $\mathbf{1 2}$ \\
\cline { 2 - 3 } & LH & 3 \\
\hline \hline \multirow{3}{*}{3} & L & 106 \\
\cline { 2 - 3 } & H & 38 \\
\cline { 2 - 3 } & LL & $\mathbf{6}$ \\
\cline { 2 - 3 } & LH & 51 \\
\hline \hline \multirow{3}{*}{4} & H & 19 \\
\cline { 2 - 3 } & LL & $\mathbf{4}$ \\
\cline { 2 - 3 } & LH & 7 \\
\hline
\end{tabular}

Setting aside the rare one-consonant roots, clear patterns emerge. LL roots are highly underrepresented in both two-consonant and three-consonant roots: only 12 of the former and 6 of the latter occur, compared to 82 and $106 \mathrm{~L}$ and 52 and $38 \mathrm{H}$, respectively. The seeming anomalistic lack of two-consonant LH roots (only 3 are attested, compared to 51 three-consonant LH roots) is likely due to the extreme rarity of roots ending in a long vowel in Chukchansi (less than one percent of the lexicon); /CVCV:/ roots are penalized by whatever force militates against root-final long vowels. Having accounted for the lack of /CVCV:/ roots, the rarity of LL verb roots is glaringly apparent; while the other root types are fairly common, LL is restricted, comprising less than six percent of Chukchansi verb roots. Moreover, several roots have been accidentally mislabeled as LL (due to incorrect transcription of a long vowel). When checked, these roots are actually $\mathrm{H}$ or LH; it is quite possible that more of the small number of LL roots have been mistranscribed (as transcription and lexical collection is an arduous process). At any rate, it is probable that LL verb roots occur much less in the lexicon than would be expected by chance.

On the other hand, L roots are very common in Chukchansi, comprising about half of all verb roots. This could be due to the simple structure of $\mathrm{L}$ roots, being either /CVC/ or /CVCC/. Also, L verb roots usually get parsed with an initial (L'H) or ('H) Foot, as shown by the roots /wil/ 'say' and /hadm/ 'cross'. /wil/ has an ('H) Foot before a consonant (37) and an ('LL) Foot before a vowel (38). /hadm/ has an (L'H) before a consonant (39) and an ('H) before a vowel (40).

L Root w/ ('H) Iamb: /wil-ta?/ $\rightarrow$ [('wil).ta?]

L Root w/ ('LL) Trochee: /wil-it/ $\rightarrow$ [('wi.li)t]

(39) L Root w/ (L'H) Iamb: /hadm-ta?/ $\rightarrow$ [(ha.'dim).ta?]

L Root w/ ('H) Iamb: /hadm-it/ $\rightarrow$ [('had).mit $]$

While two-consonant $\mathrm{L}$ roots do not always form good iambs, the final-stress-avoiding trochee is a common parse in Chukchansi. A non-final LL sequence is never formed with L roots, due to the shape inventory of non-final suffixes. Two-consonant $\mathrm{L}$ roots are thus more well-formed than LL roots; the data from the lexicon show a clear skew away from LL roots, supporting the actual root well-formedness scale below (41):

$$
\text { Actual Root Well-formedness Scale: H, LH, L } \prec \text { LL }
$$

As with epenthesis, this dispreference for LL sequences makes no sense if Chukchansi is trochaic, but perfect sense if it is iambic.

\section{Suffixed-Based Root Shape Change}

Suffixed-based root shape change in Chukchansi Yokuts (henceforth 'RSC') involves the appearance of an invariable root shape in the presence of certain suffixes. The suffix-based root shape is usually constant across the different underlying root shapes; therefore, the suffix-based root shape is not predictable from the underlying root shape. For example, when the agentive suffix /-ty'-/ occurs, the suffix-based root shape is always LH [CVCV:(C)], even if the underlying root shape is L (42a-b) or H (42c-d): 
RSC: [(CV.'CV:)], [(CV.'CV:).C] with Agentive /-t' -/

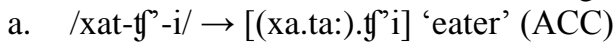

b. /lihm-t5'-Ø/ $\rightarrow$ [(le.'he:).mit']' 'runner' (NOM)

c. /ma: $x-1$ ' $-\mathrm{i} / \rightarrow\left[\left(\mathrm{ma} .{ }^{\prime} \mathrm{xa}:\right) . \mathrm{t}^{\prime} \mathrm{i}\right]$ 'collector' (ACC)

d. /be:wn-ty'-Ø/ $\rightarrow$ [(be.'we:).nit'] 'sewer' (NOM)

In Chukchansi, there are six other suffixes that cause RSC: causative /-la-/ and /-e-/, adjunctive /-Phiy-/, durative /-Pa-/, distributive /-e-/ and /-a-/, inchoative /-a-/, and causative-inchoative /-ta-/; the last three suffixes also cause the second vowel of the verb root to change to [e].

Causative: /tif $\mathrm{f}-\mathrm{la}-\mathrm{t} /$ 'cut'-CAUS-REC.PAST $\rightarrow$ [(tii.'Ja:).lat] 'just made $\mathrm{X}$ cut' Causative: /be:wn-e-t/ 'sew'-CAUS-REC.PAST $\rightarrow$ [(be.'we:).n-e-t] 'just made X sew' Adjunctive: /se:p-Phiy-?/ 'tear'-ADJT-NOM $\rightarrow$ [(si.'pa?).hiy'] 'tearing instrument/place' (NOM) Durative: /ha:tm-Pa-n'/ 'sing'-DUR-NON.PAST $\rightarrow$ [(ha.'tam').Pan'] 'is singing' Distributive: / Jawg-e-n'/ 'buy'-DIST-NON.PAST $\rightarrow$ [(fa.'we:).gen'] 'buys many X-es' Distributive: /lihm-a-n'/ 'run'-DIST-NON.PAST $\rightarrow$ [(le.'he:).man'] 'runs around' Inchoative: /gays-a-t/ 'good'-INCH-REC.PAST $\rightarrow$ [(ga.'ye:).sat] 'just got better' Causative-Inchoative: /limk-ta-t/ 'dark'-CS.INCH-REC.PAST $\rightarrow$ [(le.'mek).tat] 'just darkened X'

One thing immediately stands out: the initial Foot of all these forms is an $\left(\mathrm{L}^{\prime} \mathrm{H}\right)$ iamb. I propose that this is no accident: RSC always results in an initial (L'H) Foot. This is counter to the received notion of Yokuts RSC from Newman (1944) and Collord (1968), whose data show several different possible forms of RSC ("stems" in their terminology). With biconsonantal roots, like /xat/, /fij $/$, /se:p/, and /ma:x/ above, the (L'H) forming epenthetic vowel [a(:)] always appears between the suffix and the last root consonant. I show this below in the forms from above, with the root material bolded and underlined (51).

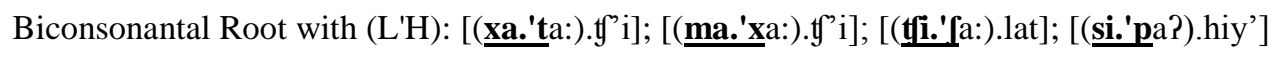

In Newman's (1944) analysis of some of these forms, the [a(:)] belong to the suffix; [a:la] and [a:f'] are just allomorphs of $/ \mathrm{la} /$ and $/ \mathrm{t} ' /$ after biconsonantal roots. Newman does analyze the [a:] in other forms as part of the "a-umlauted strong" (i.e., LH) form. Collord (1968) likewise associates the [a:] with the suffix in some of these forms. In such an analysis, the underlying root vowel always surfaces as short (52); Newman and subsequent analyses consider this a "weak" stem (Newman) or L RSC (Archangeli 1983, 1991).

$$
\text { Apparent L RSC: /se:p/ } \rightarrow \text { [sip], /ma:x/ -> [max] }
$$

Guekguezian (2011) argues that the [a(:)] in these forms is not part of the suffix; in this reanalysis, the surface forms of the suffixes are always the same with biconsonantal and triconsonantal roots, and both biconsonantal and triconsonantal roots have "disyllabic" (i.e., LH) shapes. Guekguezian (2012) accounts for the constant quality of this vowel by analyzing it as epenthetic, and thus free to assume the unmarked value of [a:] (see de Lacy 2002 for [a:] being the least marked stressed vowel). What is important is that the [a:] is epenthesized in order to provide material for the initial $\left(\mathrm{L}^{\prime} \mathrm{H}\right)$ Foot; whether the [a:] is a part of the surface exponent of the root or the suffix is immaterial, as is the target shape of the root. Regardless of the amount of material in the root (i.e., whether it has two or three consonants), the (L'H) Foot appears with all RSC-triggering suffixes. Guekguezian's $(2011,2012)$ reanalysis unifies the behavior of biconsonantal and triconsonantal stems before RSC-triggering suffixes, and dispenses with the need for L RSC in these forms.

Biconsonantal roots appear to surface as LL before the durative suffix /-?a-/ in Chukchansi. In Newman (1944), these forms have an initial LH in all dialects, including Chukchansi; the initial LH form also is found in Broadbent's (1958) Chukchansi word list. However, in Collord (1968) and currently elicited data, these forms have an initial LL (53-54):

Apparent LL RSC: /tif $\mathrm{f}-\mathrm{Pa}-\mathrm{n}$ '/ 'cut'-DUR-NPST $\rightarrow$ [tif.Ja.Pan'] "is cutting" Apparent LL RSC: /ma:x-Pa-n'/ 'collect'-DUR-NPST $\rightarrow$ [ma.xa.Pan'] “is collecting” 
I posit that these forms actually do begin with an LH, due to a preference in Chukchansi for glottal stops to occupy the coda at least partially when possible (see Howe and Pulleyblank 2001 for the preference for glottalization to occur in the coda). In these forms, I propose the glottal stop is actually ambisyllabic (55):

$$
\text { Actual LH RSC with Ambisyllabic Glottal Stop: [(ma.'xa?).Pan'], [(tgi.'Ja?).Pan'] }
$$

There is evidence that the glottal stop must occupy the coda (at least partially) in Chukchansi. First, when triconsonantal roots appear with the durative suffix, their final consonant is glottalized, if possible (56-57). This glottalization is different from the behavior of suffixes with a floating glottal in Newman (1944), where the second consonant, not the third, is glottalized. In these durative forms, the glottalization can be accounted for by linking the glottal stop of the suffix onto the preceding coda, glottalizing the root consonant.

$$
\begin{aligned}
& \text { RSC Glottalization: /lihm-?a-n'/ } \rightarrow \text { [(le.'hem').?an'] } \\
& \text { RSC Glottalization: /be:wn-?a-n'/ } \rightarrow \text { [(be.'wen').?an'] }
\end{aligned}
$$

Second, apart from the two pronominal forms [na:.?a-(k'/n)] 'we.EXCL.NOM-(DU/PL)' and [ma:..?a-(k'/n)] 'you.NOM-(DU/PL)' (often transcribed as $\left[\mathrm{naPa}\left(\mathrm{k}^{\prime} / \mathrm{n}\right)\right]$ and $\left.[\mathrm{maPa}(\mathrm{k} / \mathrm{n})]\right)$, only five forms in the dictionary show a long vowel before a glottal stop (67):

$$
\begin{aligned}
& \text { Forms with [V:?] } \\
& \text { a. [Ja.fa:.?-an] 'eye-ACC' } \\
& \text { b. [je:.?al-] 'rain' } \\
& \text { c. [p'a.ye:.?i-] 'children' } \\
& \text { d. [t'e:.?am-] 'vegetables' } \\
& \text { e. [ha.Pe:.?i-] 'clothes'. }
\end{aligned}
$$

The ubiquity of both glottal stops and long vowels in Chukchansi leaves the rarity of [V:?] forms unexplained without a principled phonological reason. If glottal stops prefer to occupy the coda, they would prevent preceding long vowels due to the CVX syllable maximum. Likewise, there is only one lexical example of a glottal stop occurring after another consonant and thus in onset position: /hid?an'-/ 'another'. While suffixinitial glottal stops may occur after another consonant, as in [(de.'Pe $\left.\int\right)$.?an'] 'is making', these are often pronounced with gemination instead, e.g., as [de'Pe $: a n ']$. The handful of forms with glottal stops in the onset alone are thus probably exceptional, and, in general, glottal stops must at least partially occupy the coda.

The only other possible cases of RSC in Chukchansi are with LH verb roots. Biconsonantal LH roots /CVCV:/ lose their final vowel before the causative (59).

$$
\text { L RSC: /pana:-la-ta?/ 'arrive'-CAUS-RM.PT } \rightarrow \text { [('pan).la.ta?] 'had made X arrive' }
$$

As indicated in $§ 5$, biconsonantal LH roots are extremely rare in Chukchansi, only three of which have been elicited, composing less than one percent of all roots. In fact, for Yokuts in general, Newman reports that these roots are only about "seven or eight percent" as common as all of the other types of roots, and are "actively being leveled out of existence" (1944:39). Due to their small number and additional aberrant phonological behavior, these roots must be irregular, as is their final vowel loss with the /-la-/ suffix.

Triconsonantal LH root /CVCV:C/ optionally lose their final vowel as well with some RSC suffixes, including the agentive $/-\mathrm{t}^{\prime}-/$. However, the LH form can also occur (60).

$$
\text { L or LH RSC: /hewe:t-ty'-Ø/ 'walk'-AGT-NOM } \rightarrow \text { [('hiw).tif'] or [(he.'we:).tif'] 'walker' (NOM) }
$$

While LH forms are always acceptable, the option of a monosyllabic form (L RSC) is mysterious. In Newman (1944), this form occurs in other Yokuts languages with a floating glottal stop, inducing glottalization on the second consonant if possible. Guekguezian (to appear) proposes that some cases of L RSC in Newman are due to a phonotactic restriction on glottalized segments, similar to that on glottal stops above, preventing the $(\mathrm{L} ' \mathrm{H})$ Foot from occurring. More research is necessary to check if this floating glottal is also present in Chukchansi words such as (60). At any rate, the restriction of this form to triconsonantal LH roots, as well as its optionality, suggests that L RSC in (60) is not a productive process. The appearance of an initial (L'H) Foot, i.e., optimal prosodic structure, is thus the only productive suffixed-based RSC process in Chukchansi. 


\section{Conclusion}

This paper has proposed that Chukchansi Yokuts is an iambic language. Its iambic properties are visible not only in its stress patterns ( $\$ 3)$, but also in patterns of vowel epenthesis $(\S 4)$, the inventory of verb root shapes (§5), and suffix-based root shape change (§6). The iambic "conspiracy" reveals itself in Chukchansi at the surface (stress and epenthesis) and in the depths (root inventory). Moreover, root shape change, superficially a morphologically-determined process in Yokuts languages (e.g., Newman 1944), reflects optimal iambic parsing. Root shape change, rather than resulting from abstract prosodic templates (e.g., Archangeli 1991), may simply fall out of general prosodic structure.

\section{References}

Adisasmito-Smith, Niken. in progress. Chukchansi-English Dictionary. Ms., California State University, Fresno.

Archangeli, Diana. 1983. The root CV-template as a property of the affix: evidence from Yawelmani. NLLT 1: $347-384$. Archangeli, Diana. 1991. Syllabification and prosodic templates in Yawelmani. NLLT 9, 231-283.

Broadbent, Sylvia. 1958. Chukchansi Vocabulary. Ms., University of California, Berkeley.

Collord, Thomas. 1968. Yokuts Grammar: Chukchansi. PhD Dissertation, University of California, Berkeley.

Crosswhite, Katherine. 1998. Segmental vs. prosodic correspondence in Chamorro. Phonology 15: 281-316.

de Lacy, Paul. 2002. The Formal Expression of Markedness. PhD Dissertation, University of Massachusetts, Amherst.

Elfner, Emily. to appear. Stress-epenthesis interactions in Harmonic Serialism. in J. McCarthy \& J. Pater (eds.), Harmonic Grammar and Harmonic Serialism. London: Equinox.

Gordon, Matt. 2004. Syllable weight. in B. Hayes, R. Kirchner, \& D. Steriade (eds.), Phonetically Based Phonology. 277-312. Cambridge University Press.

Gordon, Matt. 2006. Syllable Weight: Phonetics, Phonology, Typology. PhD Dissertation, UCLA.

Guekguezian, Peter. 2011. Topics in Chukchansi Yokuts Phonology and Morphology. Master's Thesis, California State University, Fresno.

Guekguezian, Peter. 2012. Vowel lowering and prosodic size requirements in Chukchansi Yokuts. Paper presented at NAPhC 7. Montreal, Canada. May 4-5.

Guekguezian, Peter. to appear. Verb Root Shape in Yokuts: a Consequence of Morphological and Prosodic Structure. in Proceedings of NELS 45.

Hayes, Bruce. 1995. Metrical Stress Theory: Principles and Case Studies. University of Chicago Press.

Howe, Darin and Douglas Pulleyblank. 2001. Patterns and timing of glottalisation. Phonology 18:1 45-80.

Hyde, Brett. 2007. Non-finality and weight-sensitivity. Phonology 24: 287-334.

Kager, Rene. 1993. "Alternatives to the iambic-trochaic law." NLLT 11: 381-432.

Kager, Rene. 1995. Review article of Hayes (1995). Phonology 12: 437-464.

Keer, Edward. 1999. Geminates, the OCP and the Nature of CON. PhD Dissertation. Rutgers University.

Kenstowicz, Michael and Charles Kisseberth. 1979. Generative Phonology. New York: Academic Press.

Kisseberth, Charles. 1970. On the functional unity of phonological rules. Linguistic Inquiry 1: 291-306.

McCarthy, John. 2000. Faithfulness and Prosodic Circumscription. in Joost Dekkers, Frank van der Leeuw, and Jeroen van de Weijer (eds.) Optimality Theory: Syntax, Phonology, and Acquisition. 151-189. Oxford: Oxford University Press.

McCarthy, John and Alan Prince. 1986. Prosodic Morphology. Ms., University of Massachusetts, Amherst and Brandeis University.

McCarthy, John and Alan Prince. 1993. Prosodic Morphology I: constraint interaction and satisfaction. Ms., University of Massachusetts, Amherst, and Rutgers University.

Mello, Daniel. 2012. The Stress System of Chukchansi Yokuts. Master's Thesis, California State University, Fresno.

Morén, Bruce. 1999. Distinctiveness, Coercion and Sonority: A Unified Theory of Weight. PhD Dissertation, University of Maryland.

Newman, Stanley. 1944. Yokuts Language of California. New York: Viking.

O'Connor, Ellen. 2011. Weight-driven primary stress: a stringent analysis of rime salience. Paper presented at LSA Annual Meeting, January 8, 2011.

Prince, Alan. 1990. Quantitative Consequences of Rhythmic Organization. in K. Deaton, M. Noske, and M. Ziolkowski (eds.), CLS 26-II: Papers from the Parasession on the Syllable in Phonetics and Phonology. 355-398.

Prince, Alan and Paul Smolensky. 1993/2004. Optimality Theory: Constraint Interaction in Generative Grammar. Malden, MA: Blackwell.

Selkirk, Elisabeth. 1984. Syntax and Phonology: The Relation between Sound and Structure. Cambridge, MA: MIT Press.

Zoll, Cheryl. 1993. Directionless syllabification and Ghosts in Yawelmani. Ms., University of California, Berkeley.

Zoll, Cheryl. 1996. Parsing Below the Segment in a Constraint Based Framework. PhD Dissertation, University of California, Berkeley. 